\title{
ENTRE LO TERRENAL Y LO CELESTIAL. LA SOCIEDAD DE BENEFICENCIA Y LA SOCIEDAD FILANTRÓPICA DE JUJUY: CONCEPCIONES IDEOLÓGICAS Y PROYECTOS (SIGLO XIX)
}

\author{
Between the earthly and the heavenly. The charitable society and philanthropic \\ society of Jujuy: ideological conceptions and projects (XIX century)
}

\section{Federico Medina*}

\section{Resumen}

Este trabajo pretende abordar las concepciones que fecundaron e hicieron posibles los proyectos emprendidos por la Sociedad de Beneficencia y la Sociedad Filantrópica de Jujuy durante el siglo XIX. Al mismo tiempo se estudia las relaciones que se dieron entre los agentes políticos y religiosos a fin de comprender la construcción de las esferas política y religiosa en Jujuy durante el pasado decimonónico. Se muestra que el accionar de las instituciones de beneficencia en Jujuy, entre las décadas de 1840 y 1860 , transitó entre concepciones y prácticas que apelaban al mundo celeste y al mundo terrestre.

$<$ Sociedades de Beneficencia y Filantrópica $><$ Concepciones $><$ Mundo terrenal y celestial $>$

\begin{abstract}
This paper aims to address the conceptions which fertilized and made possible the projects undertaken by the Sociedad de Beneficencia y la Sociedad Filantrópica de Jujuy in the Nineteenth century. Besides, the relationships between political and religious actors are studied in order to understand the construction of the political and religious spheres in Jujuy during the last nineteenth. It is shown that the actions of the charities in Jujuy, between the 1840s and 1860s, transited between concepts and practices that appealed to the heavenly world and the earthly world.
\end{abstract}

$<$ Sociedades de Beneficencia y Filantrópica $><$ Conceptions $><$ Earthly and heavenly world $>$

Recibido: 10/11/2014 // Aceptado: 04/06/2015

\footnotetext{
* Profesor y Licenciado en Historia por la Universidad Nacional de Salta. Becario doctoral del Conicet ICSOH-Conicet.fm0886@gmail.com.
} 
Medina. Entre lo terrenal y lo celestial. La Sociedad de Beneficencia y la Sociedad Filantrópica de Jujuy...

\section{Consideraciones iniciales ${ }^{1}$}

Las páginas que siguen tienen por objeto estudiar la beneficencia social en la provincia de Jujuy a lo largo de las décadas de 1840,1850 y 1860 . El análisis resulta significativo en tanto la beneficencia social estuvo presente en la agenda de actores eclesiásticos, del emergente estado provincial y de asociaciones de ciudadanos particulares. Por ello se convierte en un observatorio privilegiado para comprender el proceso de secularización en clave histórica. ${ }^{2}$

En el Río de la Plata colonial, la asistencia a los más necesitados de la sociedad era una tarea ejercida por algún sector de la Iglesia. En gran medida se afrontaba mediante la práctica de la caridad cristiana, en el marco de una sociedad desigual y estamental como lo era la colonial (Di Stefano, 2002: 28 y Cruz, 2009).

Con la modernidad política, los estados soberanos (provinciales y nacionales) empezarán a intervenir en el diseño y ejecución de las políticas emprendidas en materia asistencial. Es preciso señalar que este proceso de metamorfosis social se produjo a través de un conjunto de colaboraciones, remisiones continuas entre una diversidad de instancias, eclesiásticas y civiles, locales y extralocales, profesionales o personales (Castel, 2006: 59).

En el año 1820, en el territorio que luego será el de la República Argentina, los estados provinciales rioplatenses se declararon como entidades autónomas -aunque no renunciaron a unirse en un pacto constitucional- adoptando como organización política el modelo republicano de gobierno. Los intentos de unidad fracasaron, por lo que la historia política que sigue fue la de las disputas entre dos bloques y sus diferencias internas que a grandes rasgos serían: los unitarios que defendieron un régimen centralizado y los federales que propugnaron por una mayor autonomía de las provincias. A partir

\footnotetext{
${ }_{1}$ Este trabajo forma parte de los Proyectos de Investigación CIUNSa 1893/2 y 1893/3. Es financiado con una beca doctoral del Conicet, con lugar de trabajo en el ICSOH-Conicet-UNSa, cuyo título es "Política, religión y poder en Jujuy, entre los inicios de la provincia y la Organización Nacional, a través de la trayectoria de vida de Escolástico Zegada (1836-1871)" y bajo la dirección de la Dra. Valentina Ayrolo y la co-dirección de la Prof. Gabriela Caretta.

${ }^{2}$ En los últimos años, los historiadores -como investigadores en ciencias sociales, en particular sociólogos y antropólogos- dedicaron y dedican su atención en estudiar el proceso de secularización de las sociedades. Para diferentes espacios del Río de la Plata, los estudios han puesto de manifiesto las complejas y variadas relaciones entre la religión y las otras dimensiones sociales, en particular la política, focalizando especialmente en los cambios y continuidades durante el siglo XIX (Ayrolo, 2007; Barral, 2007; Di Stefano, 2004; Martínez, 2013 y Peire, 2000). Los trabajos compilados en Ayrolo, Barral y Di Stefano (2012) sintetizan los avances de los últimos años. Por su parte, la noción de secularización será entendida aquí como el proceso histórico de re-acomodo de las creencias religiosas y sus ámbitos de acción en contextos de modernidad. Proceso que a la vez fue motorizado por la "insaciabilidad de las expectaciones que suscita" en el que se observa una búsqueda permanente de medios para satisfacerlas (Hervieu-Léger, 2004: 43) creando modalidades fragmentadas, subjetivas y múltiples de intervención (Di Stefano, 2011: 5). Se puede hablar también de la pérdida de la capacidad normativa de la religión. Como resultado de este proceso se produce la consolidación de la esfera religiosa, con sus propias competencias, diferenciada de otros planos de la sociedad, como la política, la economía o la ciencia (Di Stefano, 2011). Estos campos, en palabras de Ana Teresa Martínez -retomando a Pierre Bourdieu- pueden tener intereses comunes, alianzas y clivajes compartidos (Martínez, 2012: 23-40).
} 
de 1835, Juan Manuel de Rosas consolidó un orden federal peculiar en su provincia -Buenos Aires- y lo extendió al resto de las provincias argentinas. Su caída en febrero de 1852 significó el punto de partida de la organización estatal argentina, aunque la unión política se iniciará recién en 1862 bajo la presidencia de Bartolomé Mitre. ${ }^{3}$ Ya fuera por iniciativa de los estados provinciales o por personas particulares se fundaron en el espacio rioplatense variadas instituciones asociativas. Desde mediados del siglo XIX se asistió a una "explosión asociativa", ${ }^{4}$ muchas de las cuales tuvieron como finalidad la asistencia a los más carenciados (González Bernaldo, 2008 y Di Stefano, 2002). A su vez, estas experiencias nos refieren a la constitución de una sociedad civil, ${ }^{5}$ que se fue conformando de forma paralela a los estados. Por ejemplo, formas de asociacionismo se han estudiado para Buenos Aires, Rosario, Tucumán y Jujuy. Los trabajos han llamado la atención acerca de las relaciones de poder entre la institución y los diferentes vínculos tejidos con las autoridades provinciales y eclesiásticas. En algunos casos, como la Sociedad de Beneficencia de Buenos Aires, fue una iniciativa de Bernardino Rivadavia como ministro del gobierno de Martín Rodríguez (Di Stefano, 2002). A pesar de haber sido una iniciativa laica en tanto el gobierno provincial y no las corporaciones religiosas se harían cargo de la beneficencia social (González Bernaldo, 2001: 45-72), la indagación hizo hincapié en la incidencia que los valores religiosos imprimieron a sus proyectos y la reticencias que las socias tendrían respecto a la administración rivadaviana justamente por su política en materia eclesiástica (Moreno, 2003: 431488 y Di Stefano, 2004). Para Buenos Aires, los trabajos han mostrado también que Sociedades, como las de Tucumán y Rosario, estuvieron administradas por un grupo de señoras de los sectores acomodados del espacio social. Allí, las tareas de beneficencia les permitieron contactarse con el poder político y eclesiástico, ejercer en el interior de las mismas experiencias democráticas y participar del manejo de la "cosa pública". 6

Hay estudios específicos para el caso de Jujuy. Por un lado, se ha analizado la política social emprendida en tiempos coloniales, indagando el panorama sanitario, la pobreza y la atención médica así como las diferentes entidades que se ocuparon de la asistencia: cofradías urbanas, hospitales y montepíos (Cruz, 2009). Por otro lado, los

\footnotetext{
3 Entre 1853 y 1862 coexistieron dos estados, el de la 'Confederación', liderada por Justo José de Urquiza, y el estado de Buenos Aires, que no integró esta organización más amplia por no ceder los recursos de su aduana. La bibliografía sobre ambos períodos es amplia, por lo que remitimos a tres obras de síntesis de reciente publicación: Ternavasio (2009) y Sábato (2012).

${ }^{4}$ En términos generales, la actividad asociativa se la podía visualizar, además de las Sociedades de Beneficencias o Filantrópicas, en Sociedades Literarias, de Inmigrantes, etc. Eran lugares en donde se atendían problemáticas individuales o sociales. En algunos casos, se forjaban valores y representaciones, se reafirmaban patrones culturales e identitarios y en otros se transmitían prácticas y se promocionaba el intercambio y la discusión de ideas. Ver: Di Stefano, (2002) y González Bernaldo (2008).

5 La noción hace referencia a las diferentes instituciones no gubernamentales y mayormente voluntarias que se situaron en el medio, entre el Estado y las familias o el ámbito privado. Por los estudios pioneros de Jüergen Habermas -a pesar de las críticas que recibió su planteo- se puede decir que estas instituciones, impulsadas por personas particulares reunidas como público, impulsaron el debate y estimularon el pensamiento crítico y racional (Burke, 2007: 118-122).

${ }^{6}$ Para Tucumán puede consultarse el trabajo de Cynthia Folquer (2012) y para Rosario el de Marta Bonaudo (2006). Para una mirada de conjunto y de síntesis ver Moreno (2009).
} 
Medina. Entre lo terrenal y lo celestial. La Sociedad de Beneficencia y la Sociedad Filantrópica de Jujuy...

estudios focalizaron su mirada hacia finales del siglo XIX, especialmente, en las tareas que desempeñó la Sociedad de Beneficencia como la fundación y el asilo del Buen Pastor (Mallagray, 2009). De la misma manera, y desde una perspectiva de género, el rol que cumplió esta institución en el control de la prostitución femenina (Rocabado, 2010).

Considerando estos aportes, este trabajo pretende abordar las concepciones que nutrieron e hicieron posibles los proyectos emprendidos por la Sociedad de Beneficencia y la Sociedad Filantrópica de Jujuy durante el siglo XIX. Asimismo, se indagará en los diferentes vínculos relacionales -políticos, sociales, familiares y económicos- entre los agentes que fueron parte de estas experiencias asociativas en tanto permiten explicar el momento de fundación así como el derrotero de las mismas. El objetivo es comprender la definición y ámbitos de acción de los actores eclesiásticos, del estado provincial y de actores de la sociedad civil.

Resulta relevante enmarcar el accionar de estas formas de asociacionismos en los contextos políticos de las décadas en estudio ya que la conflictividad política así como las instancias de negociación determinaron su suerte. Todo esto considerando que la mayoría de los integrantes que la compusieron participaron activamente en los entramados del poder de estos años centrales del siglo XIX.

La Sociedad de Beneficencia de Jujuy se fundó en el año 1844 por iniciativa del clérigo jujeño Escolástico Zegada (1813-1871). En 1850 fue reemplazada por una Sociedad Filantrópica que estuvo presidida por este presbítero. Ésta Sociedad funcionará durante la década de 1850. En 1861, se refunda la Sociedad de Beneficencia con otras modalidades, ya que se constituyó como una sociedad de señoras. No obstante, la voz del cura Zegada continuó haciéndose oír en la institución durante esta década.

Por ello, prestaremos especial atención a la trayectoria de vida del cura de la matriz de Jujuy Escolástico Zegada en virtud de que fue un personaje inmerso en estas tramas de poder y fue uno de los hombres que con mayor decisión y dinamismo participó en la formulación, iniciativa y ejecución de los proyectos emprendidos en beneficencia social.

Se estudian tres momentos, con la intensión de indagar similitudes y diferencias. El primero corresponde a la primera fundación de la Sociedad de Beneficencia en 1844 y hasta su clausura en 1849. El segundo está determinado por la Sociedad Filantrópica que desarrolló sus actividades en la década de 1850 . Y, finalmente, la refundación de la Sociedad de Beneficencia en 1861 y su accionar en estos años.

Para el primer momento se muestra que la Sociedad estuvo controlada por el estado provincial, bajo la administración federal de José Mariano Iturbe, y funcionó prácticamente como una oficina gubernamental dedicada al control de establecimientos de instrucción y coordinó otros emprendimientos de saneamiento urbano. A diferencia de esta Sociedad, integrada por funcionarios del estado y tres ciudadanos designados por la Legislatura, la Sociedad Filantrópica se compuso por doce varones del espacio civil y estuvo encargada de la recolección de fondos para la edificación de un hospital. Aquí la idea defilantropía, que para otros espacios como para el de Buenos Aires representó una concepción laica de la beneficencia (González Leandri, 1984), estaba anudada a los 
principios del catolicismo romano. No sólo se encontraba presidida por un clérigo sino que quienes más colaboraron en la recolección de fondos -entendidos como limosnasfueron los curas de la vicaría foránea. Por su parte, fue la feligresía la que contribuyó con más dinero. En especial, miembros de la más alta alcurnia.

El principio religioso de caridad cristiana estuvo presente en la realización de todos los proyectos. En el decreto del gobierno provincial que autorizaba la refundación de Sociedad de Beneficencia de 1861 se seguía concibiendo las suscripciones de fondos como limosnas, ahora administrada por un grupo de señoras que por su "bello sexo" podían ocuparse de la humanidad doliente.

El estado provincial participó y tuvo injerencia autorizando, controlando y aportando fondos. Sin dudas, hubo una afirmación de su poder, lo que se combinó con la presencia de la institución eclesiástica y la iniciativa perseverante del cura Zegada. Así, estudiaremos el accionar de las instituciones de beneficencia en Jujuy que, entre las décadas de 1840 y 1860, transitó entre concepciones y prácticas del mundo eclesiástico y del mundo político.

\section{Escolástico Zegada: esbozos de su trayectoria de vida}

La opción metodológica elegida para ingresar al universo de la beneficencia en Jujuy hacia mediados del siglo XIX es la trayectoria de vida de Escolástico Zegada. ${ }^{7}$ Por lo que en este apartado trazaremos un breve itinerario de la misma, ya que nos permitirá conocer los diferentes lugares de poder ocupados por el clérigo en el espacio social y las redes de relaciones que supo construir y sostener a lo largo del tiempo. Así, estos contactos posibilitaron al cura moverse con cierta comodidad en el mundo eclesiástico, en el político y en el de los negocios, todo lo cual le redituó a favor de las tareas de beneficencia.

Lo primero que debe señalarse de su experiencia de vida es que fue descendiente de los fundadores de la ciudad de San Salvador de Jujuy por vía de su abuela paterna Mercedes Rubianez. El matrimonio de Mercedes y Gregorio de Zegada logró adquirir por herencia, mercedes reales de tierras. La habilidad que tuvo Gregorio para los negocios le permitió poseer una de las mayores fortunas de Jujuy en el último cuarto del

\footnotetext{
7 Se compusieron tres biografías de Escolástico Zegada. La primera de ellas fue en el año 1869, formulada por Ángel Carranza y se adjuntó a la tercera edición del catecismo del cura publicado en el mismo año. Fue una biografía escrita en vida de Escolástico Zegada, por lo que se puede inferir se trató más bien de una autobiografía. La segunda fue escrita por Mons. Miguel Ángel Vergara (1940) y creemos fue la más importante respecto al aporte de evidencias documentales sobre la que se basó la interpretación. La obra de Vergara sirvió de base a muchos de los autores que escribieron luego sobre Zegada, fue el caso de Sánchez de Bustamante (1957). La tercera biografía corresponde a Josué Gorriti (familiar de Zegada) del año 1940, cuyo fin principal fue discutir el tratamiento que Vergara había realizado del conflicto que tuvo Zegada con el obispo de Salta Fray Buenaventura Riso Patrón. Los tres estudios sobre el cura de Jujuy que se mencionan -Carranza, Vergara y Gorriti- fueron pensados y formulados para exaltar su figura. Desde otro lugar epistemológico, estamos trabajando sobre la trayectoria de vida de Escolástico Zegada con la finalidad de identificar los escenarios del poder local donde se relacionaron agentes de la política y de la religión y se dirimieron las decisiones y prácticas que terminaron constituyendo los campos de la política y de la religión en Jujuy en el pasado decimonónico.
} 
Medina. Entre lo terrenal y lo celestial. La Sociedad de Beneficencia y la Sociedad Filantrópica de Jujuy...

siglo XVIII. Los bienes de esta primera generación fueron capitalizados y fructificados por dos de los hijos del matrimonio: José Miguel y Julián Gregorio. El primero de ellos era sacerdote y no tuvo descendencia, por lo que donó sus bienes a la única hija de su hermana, Fulgencia. La joven contrajo matrimonio con José López Villar quien atesoró gran parte de los bienes que le pertenecieron en antaño a la primera generación familiar (Peirotti, 2014). Respecto a las propiedades y bienes de Julián Gregorio se dispersaron entre varios de sus hijos. Aunque el que logró concentrar una considerable fortuna a mediados del siglo XIX fue Macedonio Graz, hijo primogénito de la hija mayor de Julián Gregorio y hermana del cura Escolástico.

Aquí es relevante retener los nombres de José López Villar y Macedonio Graz por su cercanía y apoyo a los proyectos sociales del cura. López Villar fue socio del padre de Escolástico, Julián Gregorio Zegada. El propio cura de la matriz se hizo cargo de los negocios paternos una vez que falleció su padre e incluso cuando este último ya se encontraba enfermo. Así lo muestra la planilla de cargo y data firmada por López Villar y transmitida a Escolástico Zegada en $1847 .{ }^{8}$ Por su parte, Macedonio Graz -sobrino predilecto del cura- fue su interlocutor, asesor y confidente. ${ }^{9}$ Acompañó y sostuvo todos los emprendimientos de su tío. Fue uno de los operadores a favor de la refundación de la Sociedad de Beneficencia en 1861.

Con un importante capital relacional que le proporcionaba pertenecer a una familia de élite, Escolástico Zegada también participó de la política formal de la provincia y de la floreciente Nación argentina. Ocupó cargos de representación en la Legislatura local, escenario institucional donde se dirimieron por la época los resortes del poder en un contexto fuertemente tensionado por el faccionalismo de unitarios y federales. Inició su carrera política en la Legislatura provincial en tiempos de la Liga del Norte entre los años 1840 y $1841,{ }^{10}$ siendo diputado por la capital. Luego volvió durante los años 1844-1846, 1849-1852 y 1852-1853, en este último período presidiendo el cuerpo. Tal consenso había alcanzado la figura del cura que en la revuelta unitaria de 1849 fue elegido gobernador provisorio de la provincia por unos meses. Estos meses en el poder son centrales para entender la fundación y el transitar de la Sociedad Filantrópica, como

\footnotetext{
${ }^{8}$ Esto se lo puede observar en la planilla de cargos y datas entre José López Villar y Julián Gregorio de Zegada que pasó a administrar su hijo Escolástico. Archivo del Museo Histórico del Norte (en adelante AMHN) Carta de José López Villar a Escolástico Zegada, catálogo VIII, documento 10. La vinculación entre López Villar y Escolástico Zegada se verificó también en posicionamientos políticos compartidos en las filas del unitarismo. Por ejemplo, durante el exilio de Zegada por los sucesos de 1849 -que se analizan en las páginas que siguen- fue López Villar el encargado de informar a su primo los vaivenes políticos además de haber negociado su regreso (Vergara, 1940). Por otro lado, Escolástico Zegada se encargaba de la educación de los hijos de López Villar. Hizo uso de sus redes sociales en Sucre para mandar allí a estudiar a dos hijos de López Villar. El que participó de estas mediaciones fue también Macedonio Graz, que por la hora se encontraba estudiando en Sucre. AMHN. Carta de Escolástico Zegada a Macedonio Graz, Jujuy, 28 de marzo de 1846, catálogo I, documento 39.

9 La vinculación entre ambos se la puede verificar en las correspondencias entre ambos de las décadas de 1840 y 1850 que se encuentran catalogadas en el AMHN.

${ }^{10}$ La Liga del Norte fue una alianza defensiva y ofensiva en contra del gobernador de Buenos Aires, Juan Manuel de Rosas. Las operaciones se iniciaron a principios de 1840; fue derrotada en septiembre de 1841. De ella participaron, entre otras, las provincias de Salta, Jujuy, Catamarca y La Rioja.
} 
se verá luego. Finalmente, caído el régimen federal en febrero de 1852, fue uno de los encargados de negociar la transición. ${ }^{11}$

En el año 1856 presidió la Convención Constituyente que dio como resultado la carta magna provincial ajustada a la nacional. Posteriormente, la Legislatura en mayo de 1862 lo eligió senador suplente junto a Plácido Sánchez de Bustamante. ${ }^{12}$ Zegada fue el que viajó a Buenos Aires al primer Congreso de la Argentina unificada ${ }^{13}$, oportunidad que le permitió conocer y contactarse con el presidente Bartolomé Mitre. Este vínculo se materializó en el hecho que Mitre financió el traslado de Hermanas de la Caridad y Padres Lazaristas a Jujuy, quienes se dirigieron a hacerse cargo de emprendimientos de beneficencia social. ${ }^{14}$ En 1866 integró la Convención provincial que revisó la constitución local de 1856.

Sus redes de relaciones en la política se complementaban con sus contactos en el ámbito eclesiástico. En este sentido, vale decir que fue párroco de la Iglesia Matriz desde 1839, al que sumó luego el puesto de vicario foráneo de la provincia en 1850 . A ambos cargos los mantuvo hasta 1866. En las década de 1850 se vinculó con el nuncio del Papa residente en Paraná, capital de la 'Confederación', ${ }^{15}$ Mons. Marino Marini. Escribió un catecismo religioso/político que tuvo tres ediciones (1847, 1857 y 1869). El mismo fue leído y avalado por las autoridades eclesiásticas y políticas rioplatenses de la década de 1850, incluido el Presidente Justo José de Urquiza. ${ }^{16}$ Por la información que se manejaba en Paraná, Zegada fue un candidato para ocupar una de las sillas eclesiásticas de la Confederación. ${ }^{17}$

El capital inmaterial ${ }^{18}$ heredado así como su trayectoria en los ámbitos político y eclesiástico le permitieron al cura acumular saberes, experiencias, contactos y experticia en el sentido del juego social. ${ }^{19}$ Todo ello lo posicionó en un lugar privilegiado para

${ }^{11}$ Zegada fue en ese momento, como se dijo antes, presidente de la Sala de Representantes. Su rol de operador político del momento puede verificarse en una carta que recibiera de Roque Alvarado en Tarija, dirigente de primer orden y gobernador en la década de 1850. AMHN. Carta de Roque Alvarado a Escolástico Zegada, fechada en Tarija, 11 de septiembre de 1852, catálogo IV, documento 7.

${ }^{12} \mathrm{Cf}$. Bidondo (2005). Este autor reconstruye la composición de la Legislatura de Jujuy desde su institución como provincia en 1835 hasta la década de 1980.

${ }^{13}$ Esta información se desprende de la carta enviada por Macedonio Graz a Juan María Gutiérrez, en la que le comunicaba que su tío Escolástico Zegada se dirigía a Buenos Aires a cumplir sus funciones de senador suplente. Carta de Macedonio Graz a Juan María Gutiérrez, Jujuy, 29 de mayo de 1862. Transcripta en: Archivo del Doctor Juan María Gutiérrez. Epistolario. Tomo VII. Biblioteca del Congreso, pp. 81.

${ }^{14}$ Archivo General de la Nación. Colección Casavalle. Sala VII. Expte. 19.3.4. (2298). Carta de Escolástico Zegada a Bartolomé Mitre, Jujuy, 26 de septiembre de 1864.

${ }^{15}$ Corresponde señalar que la Constitución Nacional de 1853 sancionó un Estado federal. No obstante, la documentación oficial de la época y la producción historiográfica que trabajó sobre el tema generalizó el uso 'Confederación'. Por lo que se utilizará aquí la noción y a partir de esta aclaración sin comillas.

${ }^{16}$ Medina (en prensa).

${ }^{17}$ Esto se desprende del informe elaborado por el ministro de la Confederación Facundo Zuviría al Nuncio del Papa, Mons. Marino Marini. Una información del Doctor Facundo Zuviría sobre eclesiásticos al Nuncio del Papa Marino Marini, Montevideo 6 de abril de 1856. Agradecemos el envío de esta fuente documental a la Dra. Ana Laura Lanteri.

${ }^{18}$ Nos referimos al concepto acuñado por Giovanni Levi (1990).

${ }^{19}$ Seguimos la propuesta metodológica referida a los personajes que actuaron en los procesos históricos 
Medina. Entre lo terrenal y lo celestial. La Sociedad de Beneficencia y la Sociedad Filantrópica de Jujuy...

formular, proponer, demandar y ejecutar emprendimientos de beneficencia pública. Fue uno de los ideólogos de los proyectos que se emprendieron en la provincia y gracias a sus contactos y maestría, algunos de ellos se pudieron materializar en hechos. De allí que sea relevante estudiar sus ideas relacionadas a beneficencia pública, cosa que se hará en el apartado que sigue.

\section{El catolicismo romano en las ideas y en las prácticas}

Las ideas de beneficencia y filantropía concebidas por Escolástico Zegada se sostuvieron en la noción de caridad cristiana y su programa al respecto fue vasto. En la propuesta del cura los funcionarios de Dios estaban habilitados y eran los más aptos para coordinar su ejercicio. Por ejemplo, los maestros de primeras letras y encargados de los espacios educativos que inauguraba la Sociedad de Beneficencia en la década de 1840 eran sacerdotes. La práctica de la limosna -noción del catolicismo concatenada a la de caridad- fue ejercida por miembros de la Sociedad Filantrópica para el sostén de los proyectos de beneficencia que encaraba esa experiencia asociativa. De la recolección de la limosna participaron los clérigos de la vicaría foránea de la provincia, además de los miembros laicos que conformaban la Sociedad. Por lo demás fue una práctica autorizada como tal por Decreto del poder ejecutivo al refundarse la Sociedad de Beneficencia en 1861. Así, desde representaciones y prácticas el catolicismo romano dejó su impronta en las actividades de beneficencia social llevadas a cabo en la provincia de Jujuy. En concreto, el personaje de mayor dinamismo en estas formas de asociacionismo fue el cura Zegada.

Dos escritos pensados y publicados hacia mediados del siglo XIX le permitieron al cura ampliar y formalizar sus ideas al respecto. Se trató del apartado Reflexiones religiosas y sociales dirigidas a los pueblos argentinos que se adjuntó a la segunda (1857) y tercera edición (1869) de su catecismo Instrucciones Cristianas y del ensayo Reflexiones religiosas y sociales que hace Escolástico Zegada como ministro de la Iglesia y ciudadano de la República de $1856 .^{20}$

En ambos escritos retomó el relato bíblico para marcar lo capital de la caridad cristiana en toda aspiración de ayuda social. Como se sabe, la caridad es un punto central y articulador del Nuevo Testamento, en tanto consiste en la entrega y en el servicio a los otros. En estas páginas se lee que Jesucristo brinda a los fieles un mandamiento nuevo: "Así como yo los he amado, ámense también ustedes los unos a los otros" (Juan 13, 34). Esta admonición de amor al prójimo fertilizó la reflexión de Zegada en torno a la virtud cristiana de la caridad como fuerza orientadora de las obras de beneficencia. Así, el por

como mediadores sociales. Cf. Barral (2013: 233-247).

${ }^{20}$ Las ediciones del catecismo: AMHN. Zegada, Escolástico. Instrucciones Cristianas, primera edición, Sucre, Imprenta Beche y Cia 1847. Y la tercera edición, Imprenta Pablo Coni, Buenos Aires, 1869. Biblioteca Nacional (en adelante BN). Zegada, Escolástico. Instrucciones Cristianas, segunda edición, Entre Ríos, Imprenta del Uruguay, 1857. El ensayo: Archivo y Biblioteca Históricos de Salta (en adelante ABHS). Zegada, Escolástico; Reflexiones sociales y religiosas que en nombre de la Iglesia y de la República hace Escolástico Zegada como ministro de aquella y ciudadano de esta, Imprenta del comercio, Salta, 1856. 
entonces vicario foráneo de Jujuy explicaba que dos eran las vías por las cuales se podía cooperar con las personas: desde la ayuda espiritual y desde la ayuda corporal.

En la primera arista se agrupaban todas aquellas actividades que colaboraran en la formación del espíritu. Aquí incluía, entre otras, la instrucción y la fundación de establecimientos de enseñanza. En la segunda arista contenía todas las tareas dedicadas a la ayuda corporal y material hacía los otros, como las de dar de comer al hambriento y de beber al sediento, asistir a los enfermos y atender a los desvalidos. Esta idea se sintetizó en el pasaje bíblico -citado por Zegada-21 "Bienaventurados los misericordiosos porque alcanzarán misericordia" (Mateo 5, 7). La recompensa por la ayuda ofrecida a los hermanos podía reportar por parte de Dios beneficios temporales en el presente de los benefactores así como gracias e indulgencias en el más allá.

Zegada insistió en proyectos y en acciones concretas orientadas al fomento de la instrucción pública. A la formación la ideaba para todos los sectores de la sociedad. Focalizaba en aquel grupo social que denominó vulgo, que se puede aseverar se refería a los sectores populares. En sus representaciones, la instrucción apartaría a estos grupos de la vagancia y la ociosidad. Por la instrucción, se convertirían en personas "útiles" a la sociedad. Esta noción y sus beneficios para terminar con aquellos "vicios sociales" fue sostenida por el pensamiento ilustrado y reafirmada en el siglo XIX. Se trató de ideas apropiadas por Zegada a través de los manuales de civilidad y urbanidad de la Ilustración española, de los que fue ávido lector. ${ }^{22}$

Se sabe que durante el orden colonial hispanoamericano la pobreza estuvo anudada a la caridad cristiana y a mantener ese estado social en tanto otorgar asistencia a los pobres redituaba beneficios para la vida eterna. Esta concepción fue mutando a lo largo del siglo XIX, período en el que la pobreza empezó a ser asimilada a la ignorancia, la vagancia y los vicios. Por ello, las acciones de beneficencia se orientaron a "educar" a los pobres para hacerlos "útiles" a la sociedad (Di Stefano 2004, 17). No se trataba de eliminar las desigualdades sociales ni tampoco reconocer el derecho a la asistencia en el que el poder político soberano apareciera como garante. Por el contrario, era una visión elitista de dirigir la sociedad por sobre las pasiones que podrían provocar los vicios que por lo demás eran supuestos como obstáculos que diluían las costumbres, impedían el progreso económico y el proyecto civilizacionista (González Bernaldo, 2001: 52-53). ${ }^{23}$

En este contexto se entiende la propuesta de Zegada y su defensa por la instrucción, que según sus esquemas de percepción se trataba de una obra de caridad. ${ }^{24}$

\footnotetext{
${ }^{21}$ BN. Zegada (1857: 116).

${ }^{22}$ Medina (2012: 107-122).

${ }^{23}$ En una línea más asociada al estudio de la pobreza y el pauperismo en el largo plazo y para el caso español, resulta significativa la propuesta de Pedro Casara Soto, pues propone estudiar no sólo la óptica del benefactor/asistente sino observar las peculiaridades de los asistidos. Este autor sintetiza su propuesta historiográfica en Casara Soto (2010: 569-591).

${ }^{24}$ Merece decirse que durante esta época, intelectuales católicos militantes como Feliz Frías o Facundo de Zuviría planteaban el rol moralizador del catolicismo romano y su sustentabilidad para el orden social. Con respecto al proyecto de Frías puede consultarse la obra de Tulio Halperin Dongui (2007) y en relación a Facundo de Zuviría su volumen titulado El principio religioso como elemento político, social y doméstico, Imprenta de J. Claye, París, 1861.
} 
Medina. Entre lo terrenal y lo celestial. La Sociedad de Beneficencia y la Sociedad Filantrópica de Jujuy...

A fin de lograr este objetivo, propuso diferentes estrategias, entre ellas la elaboración de un catecismo religioso para la instrucción y la fundación de colegios. Respecto a lo primero, él mismo ya había escrito un catecismo en 1847. En tanto, durante la década de 1850 se edificarían en Jujuy dos colegios, uno de mujeres y otro de varones.

Es interesante la referencia que hizo respeto de la educación femenina ya que sugería que a quienes les correspondía encargarse de esa educación eran las "damas de respeto" y no las "mozas". ${ }^{25}$ Así como sucedía en otros espacios durante el siglo XIX como el de Buenos Aires, Rosario y Tucumán, Zegada planteaba la participación femenina en la Sociedad de Beneficencia, en este caso para que se dedicaran a la educación de ese género. Con la referencia "señoras de respeto" aludía a las mujeres integrantes de la élite. Esto se llevaría a cabo con la refundación de la Sociedad de Beneficencia en 1861.

En el marco de la instrucción, el cura también fijó su atención en lo que denominó "clase culta". Aquí su preocupación estaba relacionada a que sus miembros no abandonaran el carril de la religión católica por ninguna "lectura impía". De allí, su plan se orientaba a que la Sociedad de Beneficencia se encargase de proveer "buenas obras" en contraposición a las "impías" que circulaban. Sobre todo pensaba en el adoctrinamiento que pudieren realizar los protestantes, cuyo número se incrementaría notablemente en la Argentina luego de mediados del siglo XIX.

En relación a la asistencia de las necesidades corporales, particularmente en el texto de 1856 abogaba por la fundación de diferentes establecimientos que pudieran atender las necesidades que presentaran las personas "desde la cuna hasta la tumba" ${ }^{26}$ Así nombraba la fundación de instituciones que asistieran a los párvulos abandonados o a los niños que sus padres no pudieran criarlos. De la misma manera, refería a hogares en donde "el enfermo, el inválido, el náufrago, el mendigo, el anciano, la mujer despreciada" ${ }^{27}$ encontraran asistencia. Es preciso anotar que aquí Zegada hacía referencia a las personas incapaces de trabajar, ya que en todos sus escritos insistió incansablemente en el valor del trabajo.

Asimismo y con la idea de "corregir las desviaciones de algunas mujeres" planteaba la necesidad de fundar un hospicio. En particular, orientado a aquellas mujeres que resultaran punibles por la justicia y para que encontraran contención las "mujeres públicas". Allí, las asiladas podían "moralizarse" en los moldes del catolicismo y a la par aprender oficios "propios de su sexo" como los vinculados a la costura, a las telas $\mathrm{y}$ al lavado.

Las apuestas de Zegada y su defensa indeclinable a favor de la caridad se las pueden encuadrar en los cambios experimentados promediando el siglo XIX. Por un lado, teniendo en cuenta la formación de formación de los estados (provincial y nacional) y su demanda e injerencia en la asistencia a los más necesitados. Por otro

${ }^{25}$ AMHN. Carta de Escolástico Zegada a Macedonio Graz, Jujuy, 28 de septiembre de 1851, catálogo IV, documento 42.

${ }^{26}$ ABHS. Zegada (1856: 7).

${ }^{27}$ ABHS. Zegada (1856: 7). 
lado, considerando las críticas a escala global de las élites intelectuales y culturales que cuestionaban el poder de la Iglesia y su práctica caritativa.

Respecto al primer punto, era el Estado provincial el que aprobó la fundación tanto de la Sociedad de Beneficencia como de la Filantrópica. El aval era la condición para que aportara fondos para los emprendimientos. De la misma manera se aseguró que las comisiones directivas estuviesen integradas por algún personal de su dirigencia o de solicitar informes periódicos de las actividades que se llevaban a cabo sobre todo el destino del dinero aportado. De allí la inquietud de Zegada de no perder ámbitos de influencia.

De los escritos del cura se puede ver que estaba atento a las interpelaciones a escala global que cuestionaban la ayuda social de la Iglesia. Estas discusiones le llegaban a Zegada a través de dos autores muy leídos por él que defendían a brazo partido la participación de la Iglesia y sus agentes en la vida social. Nos referimos a Jaime Balmes y a Francois de Chateaubriand. ${ }^{28}$ Ambos contra argumentaban la postura de ciertos pensadores como Montesquieu quien decía que la asistencia a los más necesitados era una responsabilidad del Estado y no de la caridad cristiana ${ }^{29}$ o de Kant que invitaba a los hombres a librarse de las tutelas y a servirse de sí mismos. ${ }^{30}$

Los cambios impuestos por la economía de mercado y sus consecuencias como el desempleo o el pauperismo coadyuvaron a definir una nueva concepción que respondiera a los problemas sociales, a saber, aludimos a la filantropía. En la época la noción era conceptualizada como laica, en el sentido que su funcionalidad no se encontraba vinculada a ninguna religión, buscaba un equilibrio entre el Estado y la iniciativa privada para moralizar a los sectores populares y estudiar soluciones desde el punto de vista "científico" de sus males (González Leandri, 1984). Por ello, Chateaubriand dirá que la filantropía era la cara falsa de la caridad. Autores como éste eran leídos vorazmente por Zegada, apropiaciones que le permitieron defender la dimensión religiosa en los proyectos sociales, incluidos los emprendidos por el estado provincial de Jujuy. No en vano el cura Zegada se refirió en estos términos al respecto:

"Si pues los filósofos, y demás profesores de sistemas humanitarios, se proponen en verdad ejercer la beneficencia con sus semejantes ¿qué mayor bien podrán hacerles que propender a que se propague nuestra Religión (...)? (...) Todas las ideas de filantropía, beneficencia, caballería, decencia, justicia, igual-

\footnotetext{
${ }^{28}$ Jaime Balmes (1810-1848) y Francois de Chateaubriand (1778-1848). Español el primero y francés el segundo, ambos fueron dos apologistas de la religión católica que ensayaron repuestas a las interpelaciones de la modernidad liberal y a las críticas de los movimientos reformistas. Por la lista de "libros útiles" que Zegada recomendó al final de su catecismo así como citas explícitas en su producción escrita, se puede decir que conoció algunas de sus obras. De Balmes recomendaba entre otras obras: El Protestantismo comparado por con el Catolicismo, El católico y El criterio. De Chateaubriand: El genio del cristianismo en dos tomos. Cf. BN. Zegada (1857: 465).

${ }^{29}$ Montesquieu. 2012 [1747]. El espíritu de las leyes, capitulo XXIX, Alianza editorial.

${ }^{30}$ Kant, Immanuel. 2010 [1784]. ¿Qué es la ilustración?, Prometeo, Buenos Aires.
} 
dad, libertad con lo que se gloría la presente civilización ¿no son las que él [Evangelio] ha promulgado desde su origen?". ${ }^{31}$

Así reafirmaba su posición de no separar la idea evangélica de caridad para ejercer de "verdad" la beneficencia con los semejantes, que por lo demás era una forma de propagar la religión católica. Zegada y las altas autoridades eclesiásticas rioplatenses de la década de 1850 temían por el ingreso y profesión de otros dogmas, habilitados por la Constitución de 1853. Así como a las críticas anticlericales de los enemigos de la religión que se profundizarían a partir de la década de 1860 (Di Stefano, 2010: 191246). ${ }^{32}$

Por su parte, ganar el espacio público con obras de beneficencia fundadas en la visión del catolicismo era un signo de que la sociedad estaba cambiando y la religión debía de reacomodarse a las nuevas exigencias de los tiempos. Los funcionarios y agentes laicos de la religión debieron idear e intervenir desde nuevas modalidades (Hervieu Leger, 2004). Estos cambios fueron visualizados por Zegada, pues convocaba a los fieles a colaborar en estas tareas de beneficencia. Posición que se articuló a lo que se estaba produciendo en el espacio rioplatense. Desde mediados del siglo XIX, muchos laicos empezaron a conformar comisiones pro-templos a fin de edificar capillas y las actividades de culto (Lida, 2006: 51-75 y Ábalo, 2012: 5-26). También desde mediados de la centuria se comenzará a ver el desarrollo de una prensa católica (Lida, 2006: 5175).

Como se verá a continuación, la presencia religiosa no estuvo ajena a las experiencias asociativas de la provincia de Jujuy. Sus agentes y defensores -Zegada apareció como figura central- negociaron y acordaron con funcionaros del estado provincial así como con personajes particulares del incipiente espacio público. Todo ello en un caldeado clima de tensión política.

\section{Sociedad de Beneficencia, 1844-1850}

La primera experiencia asociativa que estudiamos se desarrolló en momentos en los cuales el Estado provincial buscó definir y reorganizar su ingeniería institucional, considerando que se constituyó como tal hacia finales de 1834 al separarse de la jurisdicción de Salta y erigirse como provincia autónoma. Todo esto en medio de fuertes tensiones que alteraron el orden social y político en más de una oportunidad. ${ }^{33}$

\footnotetext{
${ }^{31}$ BN. Zegada (1857: 365-366).

${ }^{32}$ Nos referimos al por entonces obispos "electos" de Salta y Litoral, José Eusebio Colobres y José Leonardo Acevedo, al provisor de la diócesis de Cuyo Timoteo Maradona, al obispo de Buenos Aires Mariano Escalada y al Nuncio del Papa residente desde 1857 en la Confederación Marino Marini. Todos ellos leyeron el catecismo del cura Zegada e intercambiaron correspondencia (Medina, en prensa).

${ }^{33}$ Por un lado, las disputas entre unitarios y federales se vivenciaron en conspiraciones y asaltos permanentes al poder. Dos revueltas de unitarios tuvieron éxito en 1840 y en 1849, ya que interrumpieron la continuidad legal del gobierno federal de José Mariano Iturbe. Mientras que otras dos fueron sofocadas en la Puna en 1843 y 1845 . Por otro lado, se deben agregar los ataques de los indígenas del Chaco que ingresaron a Jujuy por la zona de Orán, localidad perteneciente a Salta (Delgado, 1993).
} 
En esta compleja trama desplegó sus actividades la Sociedad de Beneficencia. El análisis de su composición y propuestas muestra que existieron puntos de negociación y acercamiento entre la dirigencia política, convirtiéndose así en un espacio donde unitarios y federales acordaron posiciones de actuación social. Fue importante el apoyo del Estado y la participación del cura de la Iglesia local, Escolástico Zegada, en la puesta en práctica de los proyectos así como en su rol de articulador en el interior de la misma. En tal sentido, fue determinante la red de relaciones sociales, políticas y familiares que integraba el cura.

Así pues, la Sociedad se fundó el 14 de enero de 1844 por Ley de la Legislatura provincial. ${ }^{34} \mathrm{~A}$ su vez la Ley estaba respaldaba en el artículo 37 del Estatuto provincial que prescribía expresamente como una de las atribuciones del Poder Ejecutivo crear comisiones de ciudadanos en la ciudad y en la campaña para que presentasen proyectos de "adelantamiento" en diferentes áreas, entre ellas, se nombraban los ramos de agricultura, comercio, ciencias, artes. ${ }^{35}$ La iniciativa privada de individuos particulares debía ser aprobada y convalidada por el poder político. De acuerdo a la Ley de creación de la Sociedad, la misma debía estar presidida por el gobernador de la provincia e integrada por seis vocales: el juez de primera nominación, el procurador de la ciudad, el cura párroco de la matriz y tres ciudadanos elegidos por la Legislatura. ${ }^{36}$ Teniendo en cuenta los cargos ocupados por los tres primeros vocales, la Sociedad contaba con personas que por sus funciones tendrían que conocer las problemáticas y las necesidades sociales de la población que por la época se encontraba en lento crecimiento (Gil Montero, 1995: 57-80).

El cura párroco -que además fue el que tuvo la iniciativa de fundación- conocía a la feligresía de la ciudad en tanto llevaba el registro de bautismo, casamientos y entierros. A esto le podemos sumar la información e influencia que le brindaba el confesionario. Por su parte, el procurador de la ciudad tuvo la función en esos años de ocuparse de los menores y de los pobres. ${ }^{37}$ En tanto el juez de primera nominación atendió todos los litigios relacionados a causas civiles y criminales.

Ahora bien, ¿quiénes ocuparon estos cargos? Como se adelantó, el poder ejecutivo estaba ocupado por José Mariano Iturbe, quien presidió la Sociedad. El cura párroco de la matriz fue el habilidoso Zegada. En tanto, en 1847 era procurador de la ciudad José de la Quintana ${ }^{38}$ y juez de primera nominación Juan Ignacio del Portal. ${ }^{39}$ Por

${ }^{34}$ Ley sancionada el 14 de enero de 1844. En: Registro Oficial. Compilación de Leyes y decretos de la Provincia de Jujuy, tomo I, 1884, p. 176.

${ }^{35}$ Ley sancionada el 14 de enero de 1844. En: Registro Oficial. Compilación de Leyes y decretos de la Provincia de Jujuy, tomo I, 1884, p. 106.

${ }^{36}$ Ley sancionada el 14 de enero de 1844. En: Registro Oficial. Compilación de Leyes y decretos de la Provincia de Jujuy, tomo I, 1884, p. 176.

${ }^{37}$ Estatuto Provincial, sección sexta del Poder Judicial, artículo 46. En: Registro Oficial. Compilación de Leyes y decretos de la Provincia de Jujuy, tomo I, 1884, p. 107.

${ }^{38}$ Decreto del gobernador Mariano Iturbe del 24 de diciembre de 1847, artículo 3. En: Registro Oficial. Compilación de Leyes y decretos de la Provincia de Jujuy, tomo I, 1884, p. 222.

${ }^{39}$ Esta información se desprende de un acto oficial firmado por Juan Ignacio del Portal como juez de Primera Nominación en julio de 1844 y no hay registros de otros nombramientos posteriores. AMHN, 
Medina. Entre lo terrenal y lo celestial. La Sociedad de Beneficencia y la Sociedad Filantrópica de Jujuy...

su parte, los ciudadanos nombrados por el Poder Ejecutivo -según la Ley de creación votada por unanimidad en la Legislatura- fueron José López Villar, Mariano González e Ignacio Noble Carrillo, que a la sazón en ese momento eran representantes de la Sala. ${ }^{40}$

Si consideramos las trayectorias de estos miembros se puede sugerir que la mayoría de ellos tenían simpatías unitarias, participaron en la revuelta que interrumpió la continuidad institucional en el gobierno de la provincia removiéndolo al propio gobernador Mariano Iturbe en 1840. Luego, participaron de la Legislatura unitaria que le quitó al gobernador de Buenos Aires Juan Manuel de Rosas el manejo de las relaciones exteriores de la Confederación Argentina y acompañaron la Liga del Norte. ${ }^{41}$ Asimismo, apoyaron decididamente el movimiento que derribó nuevamente el gobierno de Iturbe en 1849 y eligió gobernador interino de la provincia a Escolástico Zegada. ${ }^{42}$

Hubo personajes que fueron cercanos a estos hombres sin mostrar una actitud decidida; fue el caso del Procurador y abogado José de la Quintana miembro de una familia febrilmente antifederal. ${ }^{43}$ Por su parte, Mariano González presentó una trayectoria política más próxima al federalismo ya que acompañó las medidas y las decisiones del gobernador Iturbe hasta el final de su mandato en febrero de1852. ${ }^{44}$ Además algunos de ellos estaban vinculados familiarmente: como ya se adelantó, el cura Zegada era primo político de José López Villar. Mientras que el hijo de Ignacio Noble Carrillo, también llamado Ignacio, se casó en primeras y segundas nupcias con dos sobrinas directas del cura. ${ }^{45}$ López Villar y Carrillo mantuvieron negocios y compartieron intereses económicos con el padre de Escolástico, Julián Gregorio de Zegada. Respecto a la posición económica de los miembros, todos eran miembros de la élite, algunos grandes propietarios. ${ }^{46}$

catalogo VII, documento 76 .

${ }^{40}$ Decreto del gobernador Mariano Iturbe del 28 de enero de 1844, artículo 2. En: Registro Oficial. Compilación de Leyes y decretos de la Provincia de Jujuy, tomo I, 1884, p. 177.

${ }^{41}$ López Villar e Ignacio Noble Carrillo firmaron el acta de la revuelta de 1840. AMHN, catálogo V, documento 83. Zegada participó de la Legislatura aunque faltó a la sesión que le quitó a Rosas el manejo de las relaciones exteriores de la Confederación. Archivo Histórico de la Legislatura. Libro de actas, 1840.

${ }^{42}$ Se trató de Ignacio Noble Carrillo y Juan Ignacio del Portal. Ver el acta del movimiento político de referencia. AGN. Carpetas de Gobierno de Jujuy 1838-1852. Sala X. 27713.

${ }^{43}$ Por ejemplo, su hermano el coronel Fermín de la Quintana participó del tribunal que juzgó y sentenció a muerte a José Mariano Iturbe. Sentencia que condenó a muerte a José Mariano Iturbe. Transcripta en: Sánchez Iturbe (1995: 204-207).

${ }^{44}$ Ejemplo de ello fue su participación en la Legislatura en 1851 en momentos en que el Ejecutivo provincial estaba a cargo de Mariano Iturbe. Esa Legislatura le confirió por unanimidad a Juan Manuel de Rosas "plenitud de facultades sin limitación alguna" para "exterminar hasta el último aliento a los rebeldes anarquistas" que lideraba el gobernador de Entre Ríos Justo José de Urquiza. Cf. Ley de la Legislatura de Jujuy, 24 de diciembre de 1851. Transcripta en: Eyzaguirre, José I. V. 1859. Los intereses católicos en América, tomo I, París, Garnier hermanos, pp. 504-508.

${ }^{45}$ En primeras nupcias con Ana María Dávila Zegada (1839) y en segundas nupcias con Luisa Graz Zegada (1845). Cf. Sánchez de Bustamante (1957).

${ }^{46}$ Según el catastro territorial de 1855 estudiado por Gustavo Paz, aparecen como grandes propietarios José López Villar, Ignacio Carrillo (hijo de Ignacio Noble) y Juan Ignacio Portal. Cf. Paz (2003: 11-22). 
De esta forma, se puede visualizar que la primera experiencia asociativa estuvo compuesta solo por hombres. Proyectaron las propuestas de la Sociedad desde la visión de su pertenencia social. Al mismo tiempo, por la función que ocupaban conocían las problemáticas sociales. En relación a posiciones políticas, tal como sucedió con el asociacionismo sanjuanino de la época ${ }^{47}$, la institución integró en su seno a unitarios y federales. Esta instancia de sociabilidad se convirtió así en un espacio en el que ambas facciones pudieron acordar y llevar adelante algunos proyectos. Aunque estos acuerdos no estuvieron exentos de escollos y terminaron sucumbiendo a los vaivenes políticos.

El Estado provincial aportó fondos para la ejecución de los proyectos y fue el encargado de controlar la administración de los fondos. ${ }^{48}$ Desde la creación de la Sociedad, el gobernador Iturbe en los discursos de apertura de las sucesivas Legislaturas que le tocó inaugurar, mostraba complacido sus avances y sus logros. ${ }^{49}$

Uno de los principales objetivos trazados por la Sociedad en estos años fue la educación de los menores. Por ello, crearon aulas de primeras letras, ética y latinidad en el ámbito de la ciudad de Jujuy. Era la comisión directiva de aquella la que proponía a las personas encargadas de estos espacios de instrucción así como la que inspeccionaba la enseñanza. Por un Decreto del Ejecutivo se recomendaba al preceptor propuesto por la Sociedad instruir a los niños en moral e higiene así como en los principales deberes de los ciudadanos en orden a "Dios, la patria, religión, autoridades y dogmas políticos". 50 Estas premisas guardaron estricta relación con las ideas propuestas por Zegada en sus escritos respecto a la educación y por el reglamento formulado por la Sociedad para todas las escuelas de primeras letras de la provincia. ${ }^{51}$

Lo verbalizado por el gobernador Iturbe en sus discursos coincidió con lo que Zegada le expresaba en 1844 a su sobrino, y futuro operador en pos de estas experiencias asociativas, Macedonio Graz que por ese momento se encontraba en Sucre. Puntualizaba que la Sociedad había logrado abrir un aula de latinidad como una forma de avanzar en contra de la "ignorancia" y a favor de la instrucción. Todo ello para "frenar la corrupción de la plebe", buscando una formación que hiciera disminuir los vicios y excesos públicos. ${ }^{52}$ Además, le expresaba a su sobrino que se planificaba la apertura de un espacio para la instrucción en ética, idiomas y derechos. ${ }^{53}$

Fueron presbíteros los que coordinaban la dirección de estos espacios de instrucción, que vale decir eran rentados con fondos del gobierno provincial. Por su formación eran los que estaban preparados y en condiciones de impartir tal enseñanza.

\footnotetext{
${ }^{47}$ Por ejemplo los gobernadores Yanzón y Nasario Benavidez implementaron una política de tolerancia con los unitarios y permitieron su participación en experiencias asociativas como la Sociedad Literaria Dramática Filarmónica. Cf. Di Stefano (2004: 41).

${ }^{48}$ Registro Oficial. Compilación de Leyes y decretos de la Provincia de Jujuy, tomo I, 1884. P. 177.

${ }^{49}$ Los diferentes discursos se los puede consultar en Sánchez Iturbe (1995).

${ }^{50}$ Registro Oficial. Compilación de Leyes y decretos de la Provincia de Jujuy, tomo I, 1884. Pp. 205-206.

${ }^{51}$ Archivo Histórico de Jujuy. Carpetas Vergara, caja nro. 2. Reglamento elaborado por la Sociedad de Beneficencia para las escuelas de primeras letras de la Provincia, 6 folios.

${ }^{52}$ AMHN. Carta de Escolástico Zegada a Macedonio Graz, Jujuy, 25 de julio de 1844, serie O, documento 43.

${ }^{53}$ AMHN. Carta de Escolástico Zegada a Macedonio Graz, Jujuy, 31 de diciembre de 1844, catálogo I, documento 27.
} 
Medina. Entre lo terrenal y lo celestial. La Sociedad de Beneficencia y la Sociedad Filantrópica de Jujuy...

Así lo deja ver el nombramiento por parte del poder ejecutivo y a propuesta de la Sociedad, de Fr. Vicente Comín quien debía de hacerse cargo del aula de latinidad y de la escuela de primeras letras de la ciudad. ${ }^{54}$ Otros clérigos que se ocuparon de estos emprendimientos durante la época fueron Isidoro López ${ }^{55}$ e Isidoro Fernández, ${ }^{56}$ ambos cercanos y confidentes del cura Zegada, ${ }^{57}$ por lo que podrían haber sido propuestos por el cura de la matriz.

La Sociedad de Beneficencia también emprendió obras de saneamiento urbano. El gobernador así lo anunciaba a la Sala de Representantes: "bajo su inmediata dirección se trabaja en una acequia de cinco leguas de distancia que proporcionará a la ciudad y a sus ejidos un caudal de agua suficientes para sus regadíos". ${ }^{58}$ Por el reglamento de la distribución del agua sancionado años posteriores se puede advertir la importancia que tuvo la correcta administración del agua y el trabajo que coadyuvó el calado de las acequias y el mantenimiento de los canales. ${ }^{59}$

Así, la Sociedad de Beneficencia terminó siendo una oficina gubernamental. Como se señaló antes, nació en un contexto donde el propio Estado se encontraba en proceso de consolidación y su economía distaba de ser opulenta. ${ }^{60}$

A pesar de que existieron acuerdos entre los integrantes de esta experiencia asociativa, la conflictividad política de la época terminó con los proyectos de la Sociedad. Así lo testimoniaron los adherentes a la revuelta unitaria de 1849 en la que participaron varios de los miembros de la Sociedad y en la que fue electo gobernador provisorio el cura de la matriz Escolástico Zegada. La revuelta impidió que asumiera el nuevo gobernador Pedro Castañeda, electo por la Legislatura y del mismo grupo político del gobernador saliente Mariano Iturbe. Estos fueron los argumentos expresados en el acta:

"[...] la supresión de hecho del Aula de idiomas y de la Sociedad de Beneficencia quebrantando y echando por tierra las

\footnotetext{
${ }^{54}$ Registro Oficial. Compilación de Leyes y decretos de la Provincia de Jujuy, tomo I, 1884. Pp. 205-206.

${ }^{55}$ Esta referencia se desprende de una carta de Escolástico Zegada a Macedonio Graz, 31 de diciembre de 1844. AMHN. Catálogo I, documento 27.

${ }^{56}$ Decreto del gobernador Mariano Iturbe del 08 de enero de 1844. En: Registro Oficial. Compilación de Leyes y decretos de la Provincia de Jujuy, tomo I, 1884, p. 346.

${ }^{57}$ En particular con el último con quien mantendría una nutrida correspondencia en la década de 1850 (Vergara, 1940).

${ }^{58}$ Discurso de Iturbe a la legislatura de Jujuy, noviembre de 1844. Transcripto en: Sánchez Iturbe (1996, 100-106).

${ }^{59}$ Reglamento de aguas del año 1852. En: Registro Oficial. Compilación de Leyes y decretos de la Provincia de Jujuy, tomo I, 1884, pp. 388 y 389

${ }^{60}$ A partir de 1834, momento en que Jujuy se constituye como provincia independiente, se empezaron a establecer los reglamentos de corte liberal que normatizaron el sistema rentístico, político y administrativo de la provincia (Conti, 2006 y Delgado-Fandos-Boto, 2006). Asimismo, los conflictos políticos y sociales como la invasión de indígenas del Chaco salteño, ocasionaron un clima permanente de movilización de tropas y erogaciones monetarias que afectaron las arcas financieras del Estado provincial. Por lo demás, durante la década de 1840 el Estado continuaba abonando deudas contraídas durante la guerra con la Confederación Peruano-Boliviana. Cf. Delgado (1994).
} 
leyes de su creación, para llevar adelante sus sistemado desentendimiento del progreso del país y su calculada oposición a toda mejora pública por más urgente y reclamado que fuese por el Pueblo [...]". ${ }^{61}$

Puede haberse tratado de un argumento que le haya permitido validar la revuelta, ya que vimos que el gobierno provincial aportó fondos para solventar algunos de los proyectos sobre todo los relacionados a instrucción y saneamiento. También por este registro y por las aspiraciones que luego tuvo la Sociedad Filantrópica, puede suponerse que los miembros demandaron una postura más expeditiva en la idealización y ejecución de proyectos que tendieran al "progreso del país" y a la "mejora pública".

La gobernación interina de Zegada duró dos meses. Sin dudas, fueron dos meses de negociación con la facción liderada por Iturbe y Castañeda en la que participó activa y decididamente el cura Zegada. En lo que a este trabajo nos ocupa, se puede suponer que uno de los puntos negociados fue la creación de la Sociedad Filantrópica y un mayor dinamismo en las actividades de beneficencia, tal cual veremos en el apartado que sigue.

\section{Sociedad Filantrópica, década de 1850}

De acuerdo a la Ley de creación sancionada el 9 de octubre de 1850 por la Sala de Representantes y refrendada por el gobernador Castañeda, la Sociedad Filantrópica tuvo como propósito colaborar con el gobierno provincial en todo lo concerniente a la beneficencia pública. Tuvo a su cargo una de las obras más ambiciosas ideadas por el cura Zegada: la conclusión de las obras del hospital emplazado en el casco urbano de la ciudad así como su administración. Además de ocuparse de los establecimientos de instrucción de la provincia, fue el propio cura de la matriz el presidente de la institución. ${ }^{62}$

Es posible conjeturar que su fundación formó parte de la política de compromiso acordada entre el gobernador Pedro Castañeda y los unitarios que tomaron las armas en febrero de 1849, instancia en la que, como se dijo más arriba, participó el propio Zegada. ${ }^{63}$ Afirma esta idea la composición de la Sociedad, la que estaba integrada por Gabriel Cuñado, Mateo Molina, Benito Bárcena, José López Villar, Mariano González, Mariano Santibáñez, Borja Fernández, Miguel Bárcena, Alejo Belaúnde, José María Bárcena, Mariano Pérez y Manuel Padilla. ${ }^{64}$ Varios de estos hombres participaron del movimiento político de febrero de 1849, entre ellos los dos dirigentes que lo lideraron: Santibáñez y Belaunde.$^{65}$ También entre estos hombres se reclutó el tribunal que condenó a muerte

${ }^{61}$ AGN. Carpetas de Gobierno de Jujuy 1838-1852. Sala X. 27713.

${ }^{62}$ Registro Oficial. Compilación de Leyes y decretos de la Provincia de Jujuy, tomo I, 1884. Pp. 258 y 259.

${ }^{63}$ Afirma Bidondo que la Legislatura se compuso en su mayoría por "unitarios", que para el siguiente período eligieron gobernador a José López Villar (Bidondo, 1980: 360 y 361).

${ }^{64}$ Registro Oficial. Compilación de Leyes y decretos de la Provincia de Jujuy, tomo I, 1884. Pp. 258 y 259.

${ }^{65}$ Además de estos actores, firmaron el acta del movimiento político de 1849: José María Bárcena, Miguel Bárcena y su yerno Manuel Padilla. Archivo General de la Nación. Carpetas de Gobierno de Jujuy 1838- 
Medina. Entre lo terrenal y lo celestial. La Sociedad de Beneficencia y la Sociedad Filantrópica de Jujuy...

a Mariano Iturbe en 1852: Gabriel Cuñado y Mariano Pérez. ${ }^{66}$ En esta dirección, los miembros de la Sociedad presentaron una mayor homogeneidad interna ya que la gran mayoría tuvo simpatías unitarias probadas en prácticas políticas concretas.

Otra característica que unió a algunos de ellos fue su vinculación familiar y económica. Por ejemplo, Miguel Bárcena era padre de Benito y José María y al mismo tiempo suegro de Manuel Padilla, que con el paso de los años se emparentaría con Macedonio Graz, al contraer este último matrimonio con su hija Filomena Padilla y Bárcena. ${ }^{67}$ Todos ellos eran cercanos al cura de la matriz, que a su vez como se dijo antes era primo y socio en negocios económicos con José López Villar, otro poderoso integrante de la Sociedad.

Como se puede apreciar, la Sociedad Filantrópica a diferencia de la de Beneficencia presentó un mayor número de integrantes, todos miembros de la élite de la provincia. Nuevamente se trató de integrantes varones que presentaron la propuesta de creación a la Sala de Representantes. Se puede apreciar un carácter más bien voluntario e individual en la participación (Di Stefano, 2002 y González Bernaldo, 2008). No se pusieron restricciones respecto a las personas que la integrarían como fue el caso de la forma asociativa estudiada en el apartado anterior que debía estar compuesta por el gobernador de la provincia, el juez de primera nominación, el cura párroco y tres ciudadanos designados por el Poder Legislativo.

Bueno es de decir que algunos miembros de la nueva asociación, como el cura Zegada, Mariano González y José López Villar formaron parte de la Sociedad de Beneficencia. Traían consigo la experiencia de haber estado ya en esa Sociedad.

Habida cuenta que la Sociedad Filantrópica debía encargarse de la gestión y administración del hospital, dos de sus miembros eran médicos: Gabriel Cuñado y Mateo Molina. En este caso, estuvieron en la dirección personas que por su profesión eran expertos en problemáticas vinculadas al tratamiento de la enfermedad.

La construcción del hospital fue en principio una iniciativa del cura Zegada. Los primeros trabajos empezaron hacia mediados de la década de 1840. En sus palabras, la fundación del hospital fue pensada para atender a los enfermos de la provincia ya que -según decía- muchos morían por falta de asistencia e incluso por carecer de un "rincón de abrigo". ${ }^{68}$ Hay indicios que con el paso de los años el hospital funcionó también como asilo de huérfanos (Vergara, 1940).

El estado provincial participó de la iniciativa. Aportó fondos desde que se emprendió la obra, que vale aclarar ya estaba iniciada al momento de fundarse la Sociedad. El gobierno de Mariano Iturbe destinó dinero del presupuesto y desde 1848

1852. Sala X. 27713.

${ }^{66} \mathrm{El}$ tercer integrante del tribunal fue José Luis del Portal, quien también integró la Sociedad Filantrópica en reemplazó de José López Villar cuando este último fue electo gobernador en 1851. AHJ. Colección Vergara, caja nro. 3. Nota del gobernador José López Villar a José Luis Portal, Jujuy, 08 de agosto de 1851.

${ }^{67}$ Esta reconstrucción puede ser verificada en Sánchez de Bustamante (1957).

${ }^{68}$ Solicitud de Escolástico Zegada a José Mariano Bárcena, mayo de 1847. Transcripta en Vergara (1940: 101). 
afectó al proyecto de construcción a los hombres penados por la justicia e incluso determinó que los mismos lograrían la disminución de sus condenas por realizar ese trabajo. Además, se le concedió el dinero ingresado al fisco provincial por multas. ${ }^{69}$

Con el paso de los años, se fijó un monto anual destinado a solventar la mantención del establecimiento. Estas políticas fueron sostenidas por el gobierno de los "conspicuos" centrado en la familia Sánchez de Bustamante quienes controlaron el poder político provincial desde 1853 y hasta promediar la década de $1870 .{ }^{70}$ Es válido decir en este punto que entre los personajes que fundaron la Sociedad Filantrópica se reclutaron varios dirigentes que ocuparían cargos de gestión de primer orden en la provincia a partir de 1853, propiciando y acercando posiciones a favor de la experiencia asociativa. Por ejemplo, José Benito Bárcena fue gobernador entre marzo de 1852 y febrero de 1853 y su ministro de gobierno fue Macedonio Graz. Bárcena luego fue ministro de gobierno de Plácido Bustamante entre 1855 y 1857 . Entre 1852 y 1853 el cura Zegada presidió la Sala de Representantes y en 1855 y 1856 la Convención Constituyente provincial.

La Ley de creación no puso restricciones respecto al accionar de la Sociedad Filantrópica, por lo que se manejó con autonomía. El artículo 4 autorizaba a abrir suscripciones voluntarias de la población, siempre y cuando lo exijan las necesidades del hospital, efectivamente así se hizo. ${ }^{71}$ Es interesante el análisis de estas suscripciones ya que algunas donaciones aparecieron consignadas como "limosnas", concepción del catolicismo romano, y eran recolectadas por los clérigos de la vicaría foránea.

Nuevamente el accionar personal del cura Zegada y sus redes de relaciones jugaron un rol de importancia. El cura supo actuar con destreza y sutileza. Esta actitud se la puede constatar en una carta a su sobrino Graz, que integraba una sociedad de este tipo en Sucre, en la que le expresaba que se tenía que manejar con habilidad para "tocar resortes" a fin de obtener fondos. ${ }^{72}$ Buscando obtener financiamiento y coordinar las actividades, el cura "tocó varios resortes".

Se destacaron dos personajes por las sumas aportadas a la empresa del hospital. Uno de ellos fue José Ignacio de Guerrico, quien fuera ministro general del gobierno provincial alineado a la Liga del Norte y amigo personal del cura, ${ }^{73}$ donó en 1847 la

\footnotetext{
${ }^{69}$ Registro Oficial. Compilación de Leyes y decretos de la Provincia de Jujuy, tomo I, 1884. P. 240.

${ }^{70} \mathrm{El}$ control fue el resultado de sus conexiones, de su preeminencia social como antigua familia de la elite y su militancia anti rosista. Se continuó la dinámica de consolidación del estado provincial en un contexto en el cual el estado nacional se encontraba en proceso de edificación. De allí que el período iniciado en 1853 fuera el de la incorporación de Jujuy a la nación y el de la nación -con sus agencias- en la provincia. En 1856 se dictó la carta magna local ajustada a la nacional de 1853, que reglamentó la administración institucional de la provincia (Paz, 2006).

${ }^{71}$ Corresponde decir que vuelto Mariano Iturbe al poder, suprimió la Sociedad Filantrópica el 15 de diciembre de 1851, un mes y medio después caía el régimen federal en Buenos Aires. Jujuy no fue la excepción, Iturbe fue sometido a juicio y luego pasado por las armas. Posteriormente, la Sociedad Filantrópica continuó funcionando en otro contexto político.

${ }^{72}$ AMHN. Carta de Escolástico Zegada a Macedonio Gras, Jujuy, 25 de julio de 1851, catálogo V, documento 32.

${ }^{73}$ Se evidencia por las correspondencias mantenidas entre ambos en 1849. Ver Vergara (1940).
} 
Medina. Entre lo terrenal y lo celestial. La Sociedad de Beneficencia y la Sociedad Filantrópica de Jujuy...

considerable suma de 3000 pesos bolivianos..$^{74}$ Otro de ellos fue Pablo Soria -hacendado de la provincia- legó al momento de su muerte en 1851 para la manutención del hospital una hacienda en el departamento de Río Negro. La hacienda fue arrendada y esa renta ingresaba a la administración hospitalaria (Vergara, 99-120). Por testimonio de Zegada la renta era de 24 pesos mensuales. ${ }^{75}$ Bueno es decir que Pablo Soria era un viejo conocido de la familia Zegada, su relación se la puede rastrear cuando se le encargó cobrar deudas de Gregorio de Zegada, abuelo de Escolástico, en Chichas (Alto Perú). ${ }^{76}$ Estas relaciones sociales muestran los contactos del cura y su círculo de influencia, los que actuaron a favor de las obras de beneficencia que emprendía en el marco de la Sociedad Filantrópica.

Por otra parte, Zegada pidió licencia para la fundación del hospital a la autoridad eclesiástica del Obispado de Salta. Esto se entiende en tanto el hospital era considerado una obra pía y también principalmente porque iba a utilizar para tal fin parte de los fondos ingresados a la Iglesia matriz y solicitar limosnas a los fieles. La limosna era una práctica religiosa que perseguía la obtención de alguna gracia divina de quien la otorgaba (Barral, 1998: 7-33). La práctica religiosa de la limosna se amalgamaba a las suscripciones que tenían como finalidad explicita la construcción de la obra hospitalaria.

La recolección de limosnas en los curatos de la vicaría foránea -que por esta época coincidía con la jurisdicción de la provincia- fue realizada por los curas párrocos. Por ejemplo, se consignaron las donaciones enviadas por Fr. Vicente Comín, del curato de Santa Bárbara, de los clérigos Alejo Marquiegui, del curato de Cochinoca, Gabriel Días, del curato de Tumbaya, Pedro Moreno, del curato de Yavi y Andrés Justiniano, del curato de Humahuaca. Por su parte, Escolástico Zegada tomaba fondos de la fábrica de la Iglesia matriz. En el cuaderno de anotaciones del cura se expresaba con claridad que las "limosnas de la Virgen y del Santísimo" se destinaban a la construcción del hospital y a su mantenimiento. ${ }^{77}$

Así pues, el hospital funcionó en la capital de Jujuy. El cura tuvo el patronato de la obra. Junto a la Sociedad Filantrópica, designaba a las autoridades del mismo. Durante todo este tiempo fue administrador del hospital Ignacio Carrillo, vinculado a Zegada en sus proyectos y familiarmente como se señaló con anterioridad.

Hacia finales de la década de 1850, al haberse concluido la construcción del hospital, la Sociedad Filantrópica dejó de tener la fuerza de sus inicios, sus funciones fueron reemplazadas por la Municipalidad. Por otro lado, los fondos de la feligresía se hicieron más dispersos y en 1863, el hospital cerró sus puertas. Durante este primer momento atendió a 1394 enfermos. Cinco años más tarde se reabriría de nuevo (Vergara, 1940).

\footnotetext{
${ }^{74} \mathrm{Su}$ biografía puede consultarse en: Sánchez de Bustamante (1847: 198).

${ }^{75}$ Así lo deja ver el informe que Zegada elevó al gobierno de la Confederación urquicista con fecha 12 de febrero de 1854, en el marco del censo eclesiástico del mismo año. Se publicó en: El Nacional Argentino, Nro 95, 20 de abril de 1854, página 2. Agradecemos el envío de esta fuente documental al Dr. Ignacio Martínez.

${ }^{76}$ El poder lo firmó la viuda de Gregorio de Zegada, María Mercedes Rubianes. Cf. Peirotti (2014: 115).

${ }^{77}$ Cuaderno de anotaciones: (Vergara, 1940: 103-115).
} 


\section{Se refunda la Sociedad de Beneficencia}

En marzo de 1861 se refundó la Sociedad de Beneficencia nuevamente por iniciativa del incansable Escolástico Zegada quien presentó la solicitud al gobierno de la provincia. La propuesta de creación recibió una muy buena recepción debido al clima político del momento, favorable al cura de la matriz. El Poder Ejecutivo local que emitió el Decreto de refundación estaba a cargo del gobernador Pedro José Portal y su ministro general era el por la hora prominente político Dr. Macedonio Graz, sobrino dilecto e interlocutor del cura Zegada.

Según el Decreto de creación esta Sociedad, a diferencia de las otras estudiadas hasta aquí, estuvo integrada solamente por mujeres. Las doce socias elegirían por votación las autoridades que coordinarían las actividades de la Sociedad. Como en otras Sociedades de Beneficencia del espacio rioplatense, se argumentaba que las mujeres por su "bello sexo" tenían nobles sentimientos en su corazón depositados por la divina naturaleza y por ello eran las más indicadas para hacerse cargo de la educación de la juventud de su mismo género así como atender al alivio de la humanidad doliente y "demás objetos de caridad". ${ }^{78}$

La idea de caridad cristiana sostuvo las actividades que emprendería la Sociedad de Beneficencia. No sólo continuaba presente la noción de caridad cristiana sino que en el artículo cuarto se la autorizaba a pedir limosna junto a la realización de rifas, la apertura de suscripciones y demás formas de recaudar fondos. ${ }^{79}$

Esta Sociedad se hizo responsable de otra de las iniciativas del cura: el colegio de educandas de Dolores. ${ }^{80}$ Proyecto ideado por Zegada hacia finales de la década de 1840 y fundado en 1858, con la presencia del gobernador Roque Alvarado y su elenco de gobierno. Para su funcionamiento el colegio recibió financiamiento del estado provincial. Es más, una vez abierta sus puertas, la Legislatura provincial dictó una ley que subvencionó una beca por cada departamento con el objetivo que esas niñas, luego de su formación, pudieran transmitir sus conocimientos en las diferentes localidades de la provincia. Las egresadas de la institución serían las primeras maestras de las escuelas de los departamentos de la provincia (Vergara, 1940: 151-167). ${ }^{81}$ De allí el interés puesto en la formación de las maestras; estas a su vez moldearían la educación formal de los ciudadanos de la República.

La Sociedad de Beneficencia debía conciliar con el cura Zegada, quien tenía el patronato del colegio otorgado por el gobierno provincial y por autoridad diocesana

\footnotetext{
${ }^{78}$ Registro Oficial. Compilación de Leyes y decretos de la Provincia de Jujuy, tomo II, 1884. Pp. 293-294.

${ }^{79}$ Registro Oficial. Compilación de Leyes y decretos de la Provincia de Jujuy, tomo II, 1884. Pp. 293-294.

${ }^{80}$ Primeramente, el colegio estaba administrado por un grupo de mujeres encabezados por María Bárbara Navarro, quien fue su primera directora. Recibía a niñas de otros espacios como Salta y Tarija, que abonaban cinco pesos mensuales por la enseñanza y el alimento, había alumnas internas y otras externas. Carta de Escolástico Zegada a Pedro Sáenz, 1860 (Vergara, 1940: 158).

${ }^{81}$ Vale decir según la Constitución provincia de 1856, la provincia se estructuraba administrativamente en once departamentos: Capital, Perico del Carmen, Perico de San Antonio, Rio Negro, Tilcara, Humahuaca, Valle Grande, Yavi, Santa Catalina, Cochinoca y Riconada.
} 
Medina. Entre lo terrenal y lo celestial. La Sociedad de Beneficencia y la Sociedad Filantrópica de Jujuy...

del Obispado de Salta, jurisdicción a la que por entonces dependía la vicaría foránea de Jujuy.

El reglamento del colegio fue aprobado por el obispo electo de Salta, José Eusebio Colombres. Un año más tarde, el colegio era visitado por el provisor en sede vacante -por fallecimiento del obispo Colombres- quien emitió un dictamen favorable en relación a las clases impartidas, el reglamento de funcionamiento y los autores que se enseñaban. ${ }^{82}$ No menor fueron las gracias espirituales concedidas por Mons. Marino Marini- delegado apostólico del Papa residente en Paraná- a las señoras que administraban el colegio así como a las alumnas.

Esto nos muestra la injerencia que en el colegio tuvieron el cura Zegada y las autoridades diocesanas. Con ello el fuerte influjo religioso que recibió la institución, considerada por lo demás como una obra pía.

En este sentido, Zegada firmó el 19 de julio de 1864 un contrato con el Superior General de la Congregación de las Hijas de la Caridad, por el cual el Superior se comprometía a enviar a Jujuy desde París a seis hermanas de la Caridad y a dos padres Lazaristas. Las hermanas llegaron ese año para hacerse cargo del colegio de Educandas y los padres inauguraron otro de varones, ya proyectado por los miembros de la Sociedad. El gobierno provincial a cargo de Pedro Portal así como el gobierno nacional, presidido por Bartolomé Mitre, colaboraron con recursos para que las hermanas y los padres llegaran a Jujuy. ${ }^{83}$

Es importante decir que estas comunidades religiosas representaron en el mundo católico occidental una nueva forma de vivir la religión que se originó en y fue una repuesta a la modernidad política (Serrano, 2008: 157). Sus diferentes intervenciones fueron una muestra que el catolicismo readecuó sus intervenciones para tener presencia en la sociedad civil. Más allá que la estadía de los religiosos en Jujuy fue breve -sólo duro dos años- colaboraron a afianzar la doctrina religiosa en el área de la instrucción pública.

Con el paso de los años, la Sociedad de Beneficencia continuaría funcionando. Por la década de 1880, la Sociedad se aventuró a gestionar la llegada de otra comunidad religiosa, las Hermanas del Buen Pastor, las que fundarían un hospicio para mujeres. La formulación del proyecto y su ejecución encontró paralelismos con lo diseñado por Escolástico Zegada y los integrantes de la Sociedad que actuaron desde 1840 (Mallagray, 2009 y Rocabado, 2010).

\footnotetext{
${ }^{82}$ Visita del provisor eclesiástico del obispado de Salta en sede vacante, junio de 1859. Transcripta en AMHN, Zegada (1869: 40-43).

${ }^{83}$ Bartolomé Mitre financió el pasaje de los religiosos de Buenos Aires a Jujuy por pedido del cura Zegada. Cf. Carta de Escolástico Zegada a Bartolomé Mitre. AGN. Colección Casavalle. Sala VII. Expte. 19.3.4. (2298). Carta de Escolástico Zegada a Bartolomé Mitre, Jujuy, 26 de septiembre de 1864.
} 


\section{Consideraciones finales}

La puerta de ingreso elegida para observar las relaciones entre religión y política en Jujuy fueron las Sociedades de Beneficencia y Filantrópica de forma articulada con la trayectoria de vida del cura Escolástico Zegada. Los diferentes lugares de poder ocupados en el espacio social le permitieron acumular saberes y experiencias que los desempeño con éxito en la resolución de los proyectos que emprendió en materia de beneficencia pública.

En los esquemas de percepción de Zegada cualquier proyecto de beneficencia estaba atravesado por la idea de caridad cristiana, a su vez sostenida en el amor al prójimo y la misericordia que se podía conseguir de parte de la divinidad. No sin razón incorporó un apartado a la reedición de su catecismo sobre esta temática. Seguramente imbuido por las lecturas de Chateaubriand y Balmes, defendió febrilmente que no se abandonara la concepción cristiana de caridad en todo proyecto de beneficencia pública que se emprendiera. De hecho, la dimensión del catolicismo romano estuvo presente de una $u$ otra manera en las actividades desempeñadas por las Sociedades de Beneficencia y Filantrópica.

Si bien su programa fue basto, ya que planeó fundar instituciones que atendieran las necesidades de la "cuna a la tumba", logró -en el marco de las Sociedades- llevar adelante algunos de ellos. Se los puede agrupar en las dos aristas que presentó y presenta la caridad cristiana: la espiritual y la corporal.

Respecto a la primera, Zegada, no se cansó en exhortar y hacer cuanto pudo a favor de la instrucción pública como manera de educar al espíritu. Era necesario que los sectores populares dejaran la ignorancia, ya que los identificaba con la vagancia, la ociosidad y los vicios. Había que lograr que sean útiles a la sociedad, idea de utilidad propia del pensamiento ilustrado que se impuso a lo largo del siglo XIX. Allí se explica la ejecución por parte de las Sociedades de aulas de idiomas, de primeras letras, un colegio de varones y la más ambiciosa obra del colegio de educandas.

Respecto a la caridad corporal, la obra más importante que analizamos fue la construcción del hospital. Funcionó fundamentalmente asistiendo a la enfermedad. Para su construcción y administración el hospital contó con la Sociedad Filantrópica durante la década de 1850 .

Por lo demás, interesa marcar que la Sociedad Filantrópica, presidida por el cura Zegada e integrada por otros varones miembros de la élite, unidos por su pertenencia social y por su distancia en momentos puntuales a los gobiernos federales de la década de 1840, como la "revolución unitaria" de 1849. Su organización se llevó a cabo con cierta autonomía del gobierno de la provincia, lo que nos permite conjeturar que se trataba de indicios de constitución de la sociedad civil local. Reafirma esta idea la sociedad de señoras que conformaban la Sociedad de Beneficencia refundada en 1861.

La idea de filantropía en otros espacios estuvo vinculada a un carácter laico en el sentido que no se anudaba a ninguna autoridad religiosa. En el caso de Jujuy, estuvo presidida por un clérigo. Además, por su accionar quienes participaron en la recolección 
Medina. Entre lo terrenal y lo celestial. La Sociedad de Beneficencia y la Sociedad Filantrópica de Jujuy...

de fondos para la construcción del hospital fueron, entre otros, los curas párrocos de la vicaría foránea de Jujuy. En las anotaciones, los fondos donados eran percibidos como limosna. Se sabe que fue una práctica religiosa y que quien otorgaba limosna esperaba obtener de la divinidad una gracia. En esta misma tónica, en virtud de la refundación de la Sociedad de Beneficencia de 1861, el decreto del gobierno provincial autorizaba a esta asociación a percibir limosnas para el sostenimiento de las instituciones que tenía a su cargo. Las mismas se combinaron con otros fondos recibidos tanto por presupuesto del Estado provincial como por donaciones particulares.

Todos los establecimientos contaron con la autorización eclesiástica, en particular, el hospital ya que para la concreción del mismo se iban a usar recursos de la Iglesia.

Así pues, la presencia religiosa en todos los emprendimientos se entiende en el marco de la re-acomodamiento del catolicismo y sus incumbencias a partir de mediados del siglo XIX así como la búsqueda permanente de nuevas modalidades de intervención social.

Se habla de un reacomodamiento del catolicismo en tanto el estado provincial no dejó librada la iniciativa y la administración de los emprendimientos ni a la Iglesia ni a particulares. Colaboró con fondos desde el primer proyecto y controló los mismos hasta el final del período estudiado. Probablemente, esto haya sido así habida cuenta que el estado provincial y el nacional se encontraban en proceso de edificación y construcción de su ingeniería administrativa. Se puede conjeturar a partir de observar el accionar de las Sociedades de Beneficencia y Filantrópica que, durante las década de 1840 y 1860 , se vivenció un proceso en el que que poder celestial y poder terrenal actuaron conjuntamente: participaron agentes religiosos y agentes políticos, la práctica de la limosna se confundió y combinó con los fondos aportados voluntaria e individualmente y los provenientes del Estado provincial.

\section{Referencias bibliográficas}

Abalo, E. 2012. "Construir la Iglesia: clero, feligresía y Estado provincial ante la edificación de templos en la vicaría foránea de Tucumán (1852-1897)". En: Bicentenario. Revista de Historia de Chile y América, Vol. 11, No 2, Santiago de Chile, pp. 5-26.

Ayrolo, V. 2007. Funcionarios de Dios y de la República: clero y política en la experiencia de las autonomías provinciales, Buenos Aires, Biblos.

Ayrolo, V.; Barral, M. E. y Di Stefano, R. Comps. 2012. Catolicismo y secularización, Buenos Aires, Biblos.

Barral, M. E. 1998. “'Limosneros de la Virgen, cuestores y cuestaciones': la recolección de la limosna en la campaña rioplatense, siglo XVIII y principios del XIX". En: Boletín del Instituto de Historia Argentina y Americana "Dr. Emilio Ravignni", $\mathrm{N}^{\circ} 18$, tercera serie, 2do semestre, pp. 7-33.

Barral, M. E. 2007. De sotanas por la Pampa. Religión y sociedad en el Buenos Aires tardocolonial, Buenos Aires, Prometeo. 
Barral, M. E. 2013. "Una historia de los que "están en el medio": los curas rurales y la polítca en la diócesis de Buenos Aires, 1730-1820”. En: Canedo, M. (coord.) Poderes intermedios en la frontera. Buenos Aires y los "entrerrios", siglos XVIII y XIX, Buenos Aires, EUMEN, pp. 233-247.

Bidondo, E. 1980. Historia de Jujuy 1535-1950, Jujuy, Plus Ultra.

Bidondo, J. 2005. Notas para la historia de la Legislatura Jujeña 1835-1985, Jujuy, Cuadernos del Duende.

Bonaudo, M. 2006. "Cuando las tuteladas tutelan. La Sociedad de Damas de Caridad (1869-1894)". En: Signos Históricos, N 15, enero-junio, México, pp. 70-97.

Burke, P. 2007. Historia y teoría social, Buenos Aires, Amorrortu ediciones.

Carranza, A. J. 1869. "Epitome sobre la vida íntima y publica del presbítero Don Escolástico Zegada”. En: Zegada, E. Instrucciones Cristianas, Buenos Aires, Imprenta de Pablo Coni.

Casara Soto, P. 2003. "Límites de la historia social clásica de la pobreza y la asistencia en España". En: Revista de História da Sociedade e da Cultura, № 10, tomo II, pp. 569-591.

Castel, R. 2006. Las metamorfosis de la cuestión social. Una crónica del salariado, Buenos Aires, Paidós.

Conti, V. (con la colaboración de Emma Raspi). 2006. "De las guerras de la Independencia a la Organización del Estado. 1810-1852”. En: Teruel, A. y Lagos, M. (dirs.) Jujuy en la Historia. De la Colonia al Siglo XX, Jujuy, UNIHR, UNJu, Editorial de la UNJu, pp. 85-138.

Cruz, E. 2009. La politica social en el Antiguo régimen, Jujuy, Purmamarka ediciones.

Delgado, F. 1993. "Estructura política, administrativa y económica del Estado provincial. Jujuy (1834-1852)”. En: Campi, Daniel (coord.) Jujuy en la historia. Avances de investigación 1, UNIHR, UNJu, pp. 79-97.

Di Stefano, R. 2002. "La formación del movimiento asociativo, 1776-1860: de las cofradías coloniales a la asociación libre". En: Historia de la iniciativa asociativa en Argentina. Versión en línea.

Di Stefano, R. 2004. El púlpito y la plaza. Clero, sociedad y politica de la monarquía católica a la República rosista, Buenos Aires, Siglo XXI editores.

Di Stefano, R. 2010. Ovejas negras. Historia de los anticlericales argentinos, Buenos Aires, Sudamericana.

Di Stefano, R. 2011. "Para una historia de la secularización y la laicidad en la Argentina", en: Quinto Sol, Vol. 15. Nro. 1. UNPam. [En línea] consultado el 15 de noviembre de 2012 http://www.unlpam.edu.ar/ojs/index.php/quintosol.

Folquer, C. 2012. "Viajeras hacia el fondo del alma. Sociabilidad, política y religiosidad en las Dominicas de Tucumán, Argentina, 1886-1911", Tesis Doctoral, Universidad de Barcelona.

Gil Montero, R. 1995. "La ciudad de Jujuy y su campaña circundante: algunos aspectos de su población entre fines del siglo XVIII y mediados del XIX”. En: Lagos, M. (coord.) Jujuy en la Historia, avances de investigación II, Jujuy, UNIHR, pp. 4356. 
Medina. Entre lo terrenal y lo celestial. La Sociedad de Beneficencia y la Sociedad Filantrópica de Jujuy...

González Bernaldo, P. 2001. "Beneficencia y gobierno en la ciudad de Buenos Aires (1821-1861)". En: Boletín del Instituto de Historia Argentina y Americana "Dr. Emilio Ravignani”, tercera serie, núm. 24, segundo semestre, Buenos Aires, pp. 45-72.

González Bernaldo, P. 2008. Civilidad y política en los orígenes de la nación argentina, Buenos Aires, FCE.

González Leandri, R. 1984. "Caridad y filantropía en la ciudad de Buenos Aires durante la segunda mitad del siglo XIX". En: Barran, José Pedro et al. Sectores populares y vida urbana, Buenos Aires, CLACSO, pp. 251-258.

Gorriti, J. 1940. Don Escolástico Zegada. Párroco de Jujuy. Vindicación a su memoria, Salta, Escuela tipográfica salesiana.

Halperin Donghi, T. 2007. Proyecto y construcción de una Nación (1846-1880), Buenos Aires, Emecé.

Hervieu-Léger, D. 2004. El peregrino y el convertido. La religión en movimiento, México, Ediciones del Helénico.

Levi, G. 1990. La herencia inmaterial. La historia de un exorcista piamontés del siglo $X V I I$, Madrid, Editorial Nerea.

Mallagray, L. 2009. Heridas por la vida. Huérfanas, prostitutas y delincuentes. Control, disciplinamiento e integración social en Jujuy (1880-1920), Jujuy, EDIUNJU.

Martínez, A. T. 2012. "Modernidad, secularización y laicidad en América Latina. Pensar los recursos teóricos desde el caso argentino". En: Caretta, G. y Zacca, I. (comps) Derroteros en la construcción de religiosidades. Sujetos, instituciones y poder en Sudamérica, siglos XVII al XX, UNSTA-CEPIHA, pp. 23-40.

Martínez, I. 2013. Una Nación para la Iglesia argentina. Construcción del Estado y jurisdicciones eclesiásticas en el siglo XIX, Buenos Aires, Academia Nacional de la Historia.

Medina, F. 2012. "Entre la Ilustración española y las ideas contrarrevolucionarias francesas: el universo intelectual de la producción escrita de Escolástico Zegada (1813-1871)". En: Caretta, G. e Zacca, I. (comp.) Derroteros en la construcción de Religiosidades. Sujetos, instituciones y poder en Sudamérica, siglos XVII al $X X$, CEPIHA, UNSTA, CONICET pp. 107-122.

Medina, F. 2014. "Construyendo consenso y legitimidad. La proyección política del catecismo de Escolástico Zegada en tiempos de la 'Confederación' Argentina (1853-1862)”. En: Hispania Sacra: LXVI, extra I, enero-junio, Madrid, pp. 373401.

Medina, F. En prensa. "Un catecismo y varias lecturas: poder político y catolicismo romano en el espacio rioplatense durante la década de 1850". En: Estudios Sociales, Santa Fe, Universidad Nacional del Litoral.

Miranda, L. 2006. "Prensa católica sociedad en la construcción de la Iglesia argentina en la segunda mitad del siglo XIX". En: Anuario de Estudios Americanos, 63, 1, enero-junio, pp. 51-75. 
Moreno, J. L. 2003. "Modernidad y tradición en la refundación de la Sociedad de Beneficencia por las damas de la élite, durante el Estado de Buenos Aires, 18521862". En: Anuario IEHS, No 18, Tandil, pp. 431-488.

Moreno, J. L. 2009. Éramos tan pobres...De la caridad colonial a la Fundación Eva Perón, Buenos Aires, Sudamericana.

Paz, G. 2006. "La provincia en la Nación, la Nación en la provincia. 1853-1918”. En: Teruel, Ana y Lagos, Marcelo (dirs.) Jujuy en la Historia, Jujuy, UNHIR, UNJu, pp. 139-184.

Peire, J. 2000. El taller de los espejos. Iglesia e imaginario 1767-1815, Buenos Aires, Editorial Claridad.

Peirotti, L. 2014. Una trama familiar. Trayectoria política y patrimonial de los ZegadaVillar, Jujuy, Editorial de la UNJu.

Rocabado, M. 2010. Dulces, Buenas y Putas. Sexo bajo control en Jujuy (1890-1930), Jujuy, Purmamarka Ediciones.

Sábato, H. 2012. Historia de la Argentina, 1852-1890. Buenos Aires, Siglo XXI editores. Sánchez de Bustamante, T. 1957. Biografías históricas de Jujuy, Tucumán. Universidad Nacional de Tucumán.

Sánchez Iturbe, H. 1995. José Mariano Iturbe, gobernador de Jujuy, Jujuy, Imprenta Minerva.

Serrano, S. 2008. ¿Qué hacer con Dios en la República? Política y secularización en Chile (1845-1885), Chile, FCE.

Ternavasio, Marcela. 2009. Historia de la Argentina, 1808-1852. Buenos Aires, Siglo XXI editores.

Teruel, A., Lagos, M. y Peirotti, L. 2006. "Los Valles orientales subtropicales: fronteras, modernización azucarera y crisis", en: Teruel, Ana y Lagos, Marcelo (directores) Jujuy en la Historia; UNHIR, UNJu, Jujuy, pp. 435-464.

Vergara, M. A. 1940. Zegada. Sacerdote y Patricio de Jujuy, Jujuy, Edición especial del Gobierno de Jujuy. 